\title{
Title:
}

\section{Observing storytellers who use rhythmic beat gestures improves children's narrative discourse performance}

\section{Authors names and affiliations:}

Ingrid Vilà-Giménez ${ }^{1}$, Alfonso Igualada ${ }^{2,1}$, Pilar Prieto ${ }^{3,1}$

${ }^{1}$ Universitat Pompeu Fabra, Dept. of Translation and Language Sciences. Roc Boronat, 138, 08018. Barcelona, Catalonia, Spain.

${ }^{2}$ Universitat Oberta de Catalunya. Rambla del Poblenou, 156, 08018. Barcelona, Catalonia, Spain.

${ }^{3}$ Institució Catalana de Recerca i Estudis Avançats (ICREA). Pg. Lluís Companys 23, 08010. Barcelona, Catalonia, Spain.

ingrid.vila@upf.edu, aigualada@uoc.edu,pilar.prieto@upf.edu

\section{Corresponding author:}

Ingrid Vilà-Giménez

ingrid.vila@upf.edu

Roc Boronat, 138. 08018 Barcelona, Catalonia, Spain.

\section{Acknowledgments:}

We would like to express our gratitude to Escola Casa Nostra (Banyoles), Escola Pública Joan Bruguera (Girona), Escola Bora Gran (Serinyà) and Escola Can Puig (Banyoles), who helped us to recruit participants for the study, and to all the participants and their families for having participated in this study. We are grateful to Dr. Aurora Bel and Dr. Wolfram Hinzen for their comments, and also to the Prosodic Studies Group in Barcelona. Special thanks to Joan Borràs-Comes for helping with the statistical analyses and to Judith Llanes-Coromina for helping with data collection. Many thanks also go to Clara Nogué and Anna Reixach who performed our stimulus recordings. We would like to thank all the audio-visual technicians at Universitat Pompeu Fabra for helping us with recording and editing. This study was approved by the ethics committee of the Universitat Pompeu Fabra, and has been funded by a research grant awarded by the Spanish Ministry of Economy and Competitiveness (FFI2015-66533-P "Intonational and gestural meaning in language") and by the Generalitat de Catalunya (2014 SGR_925) to the Prosodic Studies Group. The first 
author also acknowledges an FI grant from the Generalitat de Catalunya (ref. 2017FI_B_00297). 


\begin{abstract}
Iconic and pointing gestures are important precursors of children's early language and cognitive development. While beat gestures seem to have positive effects on the recall of information by preschoolers, little is known about the potential beneficial effects of observing beat gestures on the development of children's narrative performance. We tested forty-four 5- and 6-year-old children in a between-subject study with a pretestposttest design. Following a pretest in which they were asked to retell the story of an animated cartoon they had watched, the children were exposed to a training session in which they observed an adult telling a total of six one-minute stories under two between-subject experimental conditions: 1) a no-beat condition, where focal elements in the narratives were not highlighted by means of beat gestures; and 2) a beat condition, in which focal elements were highlighted by beat gestures. Following the training session, a posttest was administered following the same procedure as the pretest. Narrative structure scores were independently coded from recordings of the pretest and posttest and subjected to statistical comparisons. The results revealed that children who were exposed to the beat condition showed a higher gain in narrative structure scores. This study thus shows for the first time that a brief training session with beat gestures has immediate benefits for children's narrative discourse performance.
\end{abstract}




\section{Highlights:}

A brief training session with beat gestures has immediate positive effects on children's narrative discourse performance.

Children's narrative structure scores improve after the children are told stories accompanied by beat gestures.

Keywords: beat gestures; narrative discourse performance; narrative structure; between-subject training study; pretest-posttest design. 


\section{INTRODUCTION}

Gesturing is an integral part of human communication and speakers of all ages often gesture when they talk. In adult speech, co-speech gestures ${ }^{1}$ have been demonstrated to be meaningfully integrated with speech from a semantic, pragmatic, and phonological point of view (e.g., Kendon, 1980; McNeill, 1992; Levinson \& Holler, 2014; Kelly, Özyürek, \& Maris, 2010). There is convincing evidence that prosody and gestures are significant precursors of language development and communication, as they play a role in language processing (i.e., production and comprehension). Infants start using gestures to communicate prior to using language, and there is continuity in development between the children's use of gestures and their subsequent linguistic development. The use of non-verbal communication by infants and toddlers facilitates their development of oral language, as the combination of a gesture and a word (e.g., pointing at a cake while saying the words "cake", "mommy", or "eat") predicts the onset of two-word utterances (Bavin, 2014; Goldin-Meadow \& Butcher, 2003; Iverson \& Goldin-Meadow, 2005; Özçalışkan \& Goldin-Meadow, 2005). Additionally, gesture-speech combinations in which infants point at an object while saying, for example, the word "mommy" allow them to express sentence-like information before they convey this idea in speech (e.g., “mommy puppy"). Both children's speech and their gestures improve with age, and likewise gestures precede and signal oncoming changes in speech, as children expand their communicative repertoire through gesture-speech combinations (Özçalışkan \& Goldin-Meadow, 2005).

Previous literature has highlighted the close interface between co-speech gestures integrated with speech, language, and cognitive development. However, to our knowledge, the majority of gestures involved in these studies are either concrete representational (iconic and metaphoric) gestures or deictic (pointing) gestures, both of

\footnotetext{
${ }^{1}$ McNeill (1992) classified gestures into iconic, metaphoric, deictic (or pointing), and beat gestures. Iconic gestures bear a close relationship to the semantic content of the segments of speech they accompany, as they depict properties of an object, action, or scene; thus, their meaning is given by context (e.g., as a speaker says "he [bends it way back]", his/her hand appears to grip something and pull it back). Although metaphoric gestures are similar to iconic gestures, they refer to an abstract concept (e.g., to express the concept of future with a hand gesture moving forward in space). Deictic gestures are used to indicate an object, event, or location and are performed with the pointing finger (e.g., pointing at a pencil while saying, "Can I borrow that, please?”). Beat gestures are rhythmic non-representational (i.e., without semantic information about a referent) gestures-usually of the fingers or hand-that are typically associated with prominent prosodic and pragmatically important positions in natural discourse (e.g., marking the introduction of new discourse by doing short and quick flicks of the hand in one dimension, up and down, or back and forth; see Prieto et al., 2018).
} 
them types of gestures which provide a substantial semantic component or signal an external referent in space. Such gesturing may benefit the comprehension of either semantic or syntactic structures. For instance, findings reported by Theakston, Coates, and Holler (2014) showed that the use of abstract representational co-speech gestures which singled out the two participants in an event and the roles they played in it facilitated the comprehension of a complex linguistic structure ${ }^{2}$ by 3 - and 4 -year-old children. Similarly, in a comparative study undertaken by Thompson (1995), young and old adult participants listened to a varied set of spoken sentences in three conditions: an audio recording, a video-recording of the speaker speaking, and a video-recording in which the speaker simultaneously represented the semantic content of what he/she was saying with iconic gestures. The results showed that recall was enhanced in both young and old adults when the speaker used these gestures.

Studies on the beneficial effects of gestures on language and cognitive development have typically involved representational gestures, with relatively few studies also dealing with beat gestures. Unlike representational gestures, beat gestures are rhythmic non-referential hand movements associated with prominent prosodic positions in speech. Thus they do not convey referential meaning but instead signal a variety of pragmatic and discourse meanings (McNeill, 1992; see also Prieto et al., 2018). Both iconic and beat gestures have been shown to have a positive effect on adults' ability to recall information in a discourse (e.g., Kushch \& Prieto, 2016; So, Chen-Hui, \& Wei-Shan, 2012; Austin \& Sweller, 2014; Igualada, Esteve-Gibert, \& Prieto, 2017; Llanes-Coromina, Vilà-Giménez, Kushch, Borràs-Comes, \& Prieto, 2018). In So et al. (2012), both adults and 4- and 5-year-old children were presented with three different lists of verbs in three conditions (speech accompanied by either iconic gestures, beat gestures, or no gestures) and were asked to recall as many of the verbs as they could. The results showed that both groups recalled the information better when speech was accompanied by iconic gestures. However, only adults had better recall when words were accompanied with beat gestures compared with no gesture. Notwithstanding these results, three recent studies have reported that beat gestures also improve recall in children. First, Austin and Sweller (2014) found that both beat gestures and iconic gestures facilitated the recall of spatial directions in 3- to 4-year-old children. Similarly, when Igualada et al. (2017) asked 3- to 5-year-old children to retell

\footnotetext{
${ }^{2}$ In this instance, the complex structure was an object-cleft construction like It was the frog [object] that the man [subject] pushed (Theakston et al., 2014).
} 
a list of to-do things that was presented with or without beat gestures, they found that recall was significantly better in the former condition. And a recent study by LlanesCoromina et al. (2018) showed that beat gestures performed during discourse positively influenced information memorization by 4-year-old children.

In the context of second language acquisition, both iconic and beat gestures have been shown to benefit novel word learning. Tellier (2008) analyzed the impact of iconic gestures on second language word memorization with twenty French children (mean age 5;5). The children were taught eight English words in two conditions, a no-gesture condition, in which words were taught accompanied by pictures, and a gesture condition, in which words were taught accompanied by iconic gestures that were to be reproduced by the children tested in this group. The results showed that the children were able to memorize more words in the latter condition than in the former. Similarly, Kelly, McDevitt, and Esch (2009) showed that a brief training session with iconic gestures helped adult speakers to learn novel words in a foreign language. With respect to the benefits of beat gestures, a recent study by Kushch, Igualada, and Prieto (2018, in press) found that beat gestures together with prosodic prominence was the optimal combination for second language novel vocabulary learning.

Two very recent studies assessed the effects of beat gestures on narrative discourse comprehension with children, yielding contradictory results. Macoun and Sweller (2016) tested the impact of beat gestures on the discourse comprehension processes of children aged 2.5 to 5.58 years and found that they had no effect. By contrast, Llanes-Coromina et al. (2018) found that beat gestures can indeed help 5- to 6year-olds to comprehend a narrative. Yet both of these studies focused on narrative comprehension; to our knowledge, little is known about the potential beneficial effects of observing narratives produced with beat gestures on children's ability to produce subsequent narratives.

In the present study, we suggest that assessing children's narrative discourse production can provide us with novel insight about the role of training with gestures on communication, specifically in children's narrative production. In other words, we hypothesize that storytellers' gestures (specifically beat gestures) can play a role in children's observation and comprehension of narratives, thereby fostering their subsequent narrative performances. Our predictions are supported by the Gesture-forConceptualization Hypothesis recently put forth by Kita, Alibali, and Chu (2017:6) whereby “(1) gesture activates, manipulates, packages and explores spatio-motoric 
representations for the purposes of speaking and thinking" and "(2) gesture schematizes information, and this schematization process shapes these four functions". By broadening the scope of Kita et al.'s (2017) proposal to include beat gestures, we suggest that observing short narrative discourses performed with beat gestures may affect the contents of children's subsequent production of narratives, as gesture production influences how information is packaged for both thinking and speaking. In a study that is related to this suggestion, Mumford and Kita (2014) clearly showed the role of the speaker's gestures in enhancing a listener's output schematization of an object or event. Children were asked to watch a video scene in which objects were moved by a hand in a specific way (e.g., by pulling strips of cloth) into a particular configuration (e.g., aligned vertically) while an adult speaker simultaneously used a novel ambiguous verb (e.g., "Look! She is blicking!”). The novel verb could have two possible interpretations: either they referred to acting on objects in a particular manner (pushing) or they referred to the act of bringing about the end state (aligning vertically). Results showed that when the speaker emphasized the manner of action by a gesture accompanying the novel verb, the children understood the verb as referring to the manner, whereas when the gesture highlighted the end state, the children interpreted the verb as depicting the end state.

In a related fashion, listeners' schematization of information has been shown to be influenced by the speakers' use of gestures. Building on these ideas, the Gesture-AsSimulated-Action Framework (Hostetter \& Alibali, 2008) holds that gestures and speech emerge from a single embodied cognitive system in which gestures constitute simulations of action and perception (i.e., they are primordially performed without a communicative intention) that support language thinking. By definition, beat gestures are non-referential, and they have been shown to be closely linked to discourse structure. For example, Shattuck-Hufnagel, Ren, Mathew, Yuen, and Demuth (2016) claim that beat gestures not only are typically associated with focus and rhythmic marking but also function as discourse structure anchoring points. The fact that beat gestures perceptually enhance focus and discourse structure, functions that have typically been linked to prosody (Loehr, 2012; Wagner, Malisz, \& Kopp, 2014), makes them good candidates to promote abilities related to structuring and focalizing information in narratives. Along the same lines, Dimitrova, Chu, Wang, Özyürek, and Hagoort (2016) highlight the function of beats as indicators of information focus in language comprehension. In the words of Kendon (1995:247), gestures with a pragmatic 
(vs. substantial) function guide discourse organization or "express aspects of utterance structure, including the status of discourse segments with respect to one another, and the character of the 'speech act' or interactional move of the utterance". Given that beat gestures clearly fit this definition by highlighting pragmatic and linguistic functions in discourse, it is reasonable to conjecture that observing them will boost children's subsequent narrative performance.

In fact, it has already been shown that gestures of various sorts play an important role in narrative discourse development. Narratives are typically used as an ecologically valid measure of a child's language abilities, and many studies use this measure as a control against which children's language pathologies can be analyzed (e.g., Demir, Fisher, Goldin-Meadow, \& Levine, 2014; Demir, Rowe, Heller, Goldin-Meadow, \& Levine, 2015b; Duinmeijer, De Jong, \& Scheper, 2012; Demir, Levine, \& GoldinMeadow, 2010). It has been demonstrated that early acquired narrative abilities (such as being able to provide a well-structured narrative, contextual information, their own comments about the narrative events, etc.) are predictive of later literacy development, reading comprehension, and academic performance and success in school (e.g., Demir \& Küntay, 2014; Griffin, Hemphill, Camp, \& Wolf, 2004). Regarding the relationship between narrative development and gestural development, Colletta et al. (2015) investigated multimodal narrative development in 5- and 10-year-old French, American, and Italian children's narratives of a wordless cartoon and found that gesture and speech went hand in hand, with the children's use of gestures related to narrative organization developing as their verbal narratives became more complex. Moreover, the use of gestures by both adults and children in narratives has been shown to benefit children's narrative performances. In a longitudinal study by Demir, Levine, and Goldin-Meadow (2015a), 5-year-old children who expressed character viewpoint ${ }^{3}$ by means of gestures while producing verbal narratives showed greater improvement in their verbal narrative production with age compared to those children who did not produce character viewpoint gestures. Additionally, both children with early brain injury who had difficulty in structuring narrative and typically developing children were more likely to produce well-structured narrative retellings when the storyteller performed storyrelevant gestures while speaking (Demir et al., 2014).

\footnotetext{
${ }^{3}$ Following McNeill's (1992) classification, character-viewpoint gestures show first-person perspective, as the gesturer assumes the role of the character by enacting the character's actions.
} 
Taking into account the evidence suggesting that observing gestures influences listeners' schematization of information and that beat gestures highlight pragmatic functions and discourse structure, the aim of this study is to examine the potential effect of a brief training session in which children watch storytellers who accompany their storytelling with beat gestures on the children's subsequent ability to produce a narrative discourse. Following Demir et al. (2014), we will measure this narrative ability in terms of the cohesion and coherence of the narrative structures the children produce.

Many studies of children's language development have demonstrated that the basic narrative abilities emerge during the preschool years and continue to improve until roughly age 12. By contrast, the literature on the acquisition of beat gestures within narrative discourse is very relatively scarce and has primarily focused on how children gesture with beats while they are narrating (see Mathew, Yuen, \& Demuth, 2017, for a review). Although the appearance of beat gestures in bilingual children as young as 2.5 (Nicoladis, Mayberry, \& Genesee, 1999; Mayberry \& Nicoladis, 2000) has been reported, other studies have shown beat gestures in discourse emerging later, between 5 and 10 years of age (Colletta, Pellenq, \& Guidetti, 2010; Blake, Myszczyszyn, Jokel, \& Bebiroglu, 2008; Mathew et al., 2017). Through a longitudinal study with five FrenchEnglish bilingual children aged 2.5-3 years, Nicoladis et al. (1999) investigated how the combination of language and cognitive development could affect gesture development and found that beat gestures tended to be performed in more complex and longer utterances, suggesting that beat gestures "illustrate the temporal structure of utterances" (p. 524). The authors speculated that the fact that the relationship between the development verbal skills and iconic and beat gestures seemed to be weaker for the children's French than for their English "may be due to the fact that, as a group, the children's French was less developed than their English” (p. 520). In a follow-up study, Mayberry and Nicoladis (2000) carried out a longitudinal study with French-English bilingual children aged 2-3.5 in which they assessed the relationship between gesture performance and language development. Their findings showed that both iconic and beat gestures, but not pointing gestures, were significantly correlated with the children's language development. Moreover, they also found that the children started producing iconic and beat gestures at the same time they started producing their first utterances. Mathew et al. (2017) showed that, during narrative and exposition discourses, twelve 5to 7-year-old typically developing Australian English children produced beats with a 
well-defined stroke phase that resembled those performed by adults, and these beats were closely related to the prosodic organization of speech. For their part, Colletta et al. (2010) carried out a narrative task with monolingual French-speaking children aged between 6 and 10, and adults. Their results showed that the average number of nonrepresentational beat gestures with a discursive function (e.g., accompanying connectors, highlighting important linguistic units, or performing anaphoric functions) and gestures with a framing function (e.g., those which express the speaker's emotions, such as surprise) increased significantly with age, whereas the average number of other types of representational gestures did not, and that adults were significantly more likely to perform discursive and framing gestures than children. These results are consistent with the idea that the use of gestures in discourse development and narrative production co-develops with age, and that children start to produce discursive gestures with a functional meaning in narratives between 6 and 10 years of age.

The present study intends to contribute to our understanding of the relationship between language development and the observation of gestures during spoken language. More specifically, it will examine the impact of observing storytellers who accompany their storytelling with beat gestures on the re-telling performance of 5- and 6-year-old children. If beat gestures have a clear pragmatic role in highlighting discourse structure marking, we expect that children who hear stories that are accompanied by beat gestures will improve more on their subsequent narrative performance more than children who hear the same stories but see no beat gestures.

\section{METHODS}

The experiment consisted of a between-subject training paradigm with a pretest and an immediate posttest design. ${ }^{4}$ The pretest and posttest consisted of child-produced narratives, which were compared to measure improvement in the children's narrative structure.

\subsection{Participants}

Forty-seven children (25 boys and 22 girls) from the Girona area of Catalonia participated in the study. All of them were typically developing children with no prior

\footnotetext{
${ }^{4}$ The study "Observing storytellers who use rhythmic beat gestures improves children's narrative discourse performance" obtained ethics approval from the ethics committee at the Universitat Pompeu Fabra, as part of the approval of the Spanish Ministry of Economy and Competitiveness project FFI201566533-P "Intonational and gestural meaning in language".
} 
history of communication disorders in themselves or within their families. Three of the original participants were excluded from the final analysis (two girls and one boy), for the following reasons: one child did not produce any utterances at all during either pretest or posttest; technical problems occurred during the pretest recording session of the second child; and the third child was accidentally shown the same two stories in both pretest and posttest segments. Thus, the results of this study are based on data from the remaining 44 participants (mean age $=5.94 ; S D=0.57$ ). The sample size was determined post-hoc using G*Power version 3.1 (Faul, Erdfelder, Buchner, \& Lang, 2009), which showed a small- to medium-sized effect $(\alpha=.05$, power $=0.70)$ and a sample size of 42 participants.

The children were recruited from four different schools. ${ }^{5}$ The parents were informed about the main goal of the experiment and signed a form allowing their children to participate in the experiment and be video-recorded in the process. Moreover, since the experimental tasks were all going to be administered in Catalan, caregivers filled out a language exposure questionnaire (Bosch \& Sebastián-Gallés, 2001) to ensure that all participating children were coming from a context in which Catalan was the predominant language of daily use. The results of the questionnaires showed that the 44 children were exposed to Catalan daily on average about $90 \%$ of the time $(M=90.50 ; S D=9.06)$.

\subsection{Materials}

The experiment consisted of three parts: a pretest, a training session, and a posttest. The pretest and posttest materials consisted of four different animated cartoons (approximate length 41-50 s) about a small mouse ${ }^{6}$ and his friends, characters with which the child subjects were previously unfamiliar. The cartoons had no dialogue or narration, and were intended to serve as prompts for the child to produce a narrative about what he or she had seen in the cartoon. Two of these cartoons featured a single main character, whereas the other two featured two characters, but all followed the same structure, which is schematically illustrated in figure 1 (the four cartoon-based narratives can be seen in Appendix A). First, some initiating event presented a goal or challenge to the

\footnotetext{
${ }^{5}$ Children were from the Escola Casa Nostra and from the Escola Can Puig, both in Banyoles, from the Escola Pública Joan Bruguera in Girona, and from the Escola Bora Gran in Serinyà.

${ }^{6}$ The cartoons used in this study were taken from online animations available at http://www.wdrmaus.de and were also used in studies such as Demir et al. (2014) and Alibali, Evans, Hostetter, Ryan, and Mainela-Arnold (2009).
} 
protagonist. This provoked an action on the character's part, which led to a particular outcome, whether successful or not (the structure was based on the narratives used in studies such as Demir et al., 2014, and Demir et al., 2015a). Two of these cartoons were used for the pretest and two different ones were used for the posttest. In each case, the first cartoon was one that featured one character, the second cartoon one that featured two.

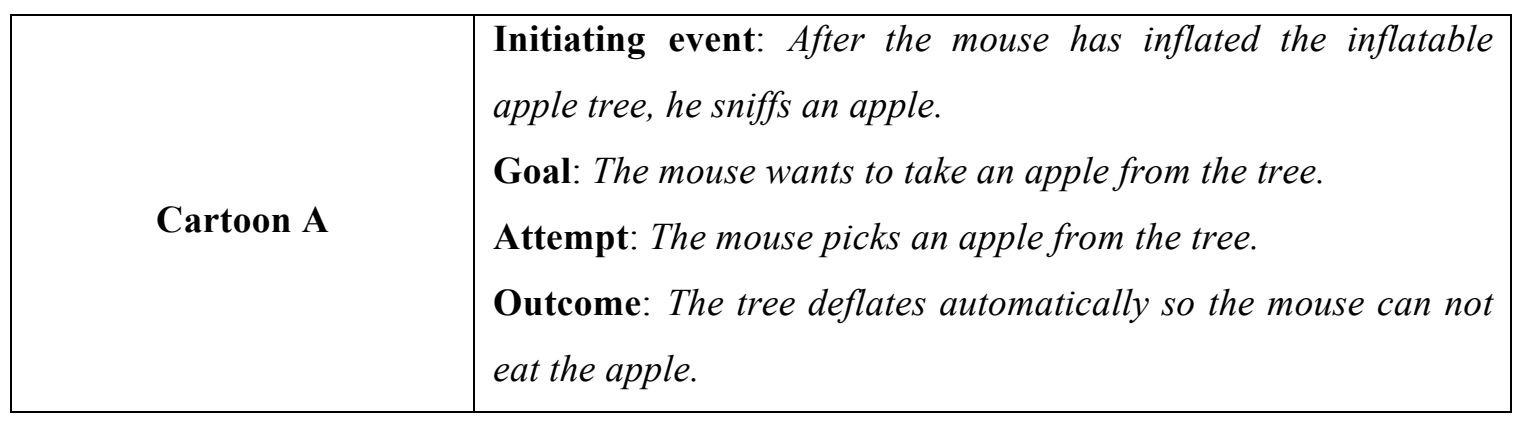

Figure 1. Narrative structure of one of the cartoon stories.

The training session between pretest and posttest involved the use of 24 videorecordings in which two adult female storytellers told different stories. In twelve of these recordings, the storytellers used beat gestures for emphasis and in the other twelve they did not. Each training story was about an animal that lived on a farm and followed a narrative structure similar to that seen in the animated cartoons. An English translation of one of these stories is shown in (1) (and translations of all six are reproduced in Appendix B).

(1) Once upon a time, a duck was walking to school. Suddenly, it started to rain, and the duck didn't have an umbrella. In the end, he came up with a solution: he put his hood on his head to protect himself from the rain.

The preparation of these video-recordings was a fairly elaborate process, which is described in the following section.

\subsubsection{Preliminary study}

Before recording the final audio-visual stimuli for the training session, we carried out a preliminary study intended to ensure the ecological validity of our materials. In this preliminary study, two female preschool teachers were video-recorded as they performed dramatic readings of five short narratives (which were similar in form to the 
stories ultimately used in the recordings - see 2.2.2 below) as if speaking to a group of young children. Then, with reference to the MIT Gesture Studies Coding Manual ${ }^{7}$, the video-recordings were analyzed to identify the beat gestures the two speakers had spontaneously produced as they narrated. The two most frequently occurring types of beat gestures used by the speakers were a palm-up movement of the hands outwards at waist level (see figure 2, left panel), and a movement of the hands inwards towards the waist, with palms facing the body, fingertips of the two hands sometimes touching (see figure 2, right panel). Both hand movements were typically associated with a head nod, a widening of the eyes, and a raising of the eyebrows. Interestingly, in our preliminary study, while the open-palm outward gesture accompanied either focal content words (e.g., a duck, rain, umbrella in (1) above $)^{8}$ or discourse markers such as metadiscursive (once upon a time, suddenly, in the end), temporal (before, until), contrastive (but), causal (because), consecutive (therefore, that way), or conditional connectors (otherwise), ${ }^{9}$ the inward gesture occurred only with focal content words. We therefore decided that in the subsequent recordings of stimulus materials we would use the outward movement to emphasize discourse markers and the inward movement to mark focal content words stimuli (see section 2.2.2 below).
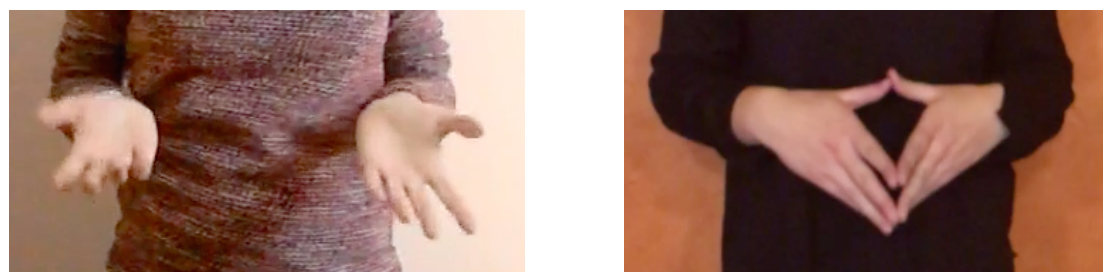

Figure 2. Examples of the most frequently performed beat gestures from the preliminary study. Left panel: the outward hand movement. Right panel: the inward hand movement.

\subsubsection{Recordings of experimental materials}

For the final video materials, six stories were created along the lines of those used in the preliminary study, each one featuring a farm animal that is confronted by a challenge that it must somehow resolve (see Appendix B for English translations of all six

\footnotetext{
${ }^{7}$ Available at http://web.mit.edu/pelire/www/manual/ (Shattuck-Hufnagel et al., 2016).

${ }^{8}$ Content words are words with lexical meaning, typically nouns, verbs, adjectives, or adverbs. In this study, the stroke phase of beat gestures was typically associated with the content words.

${ }^{9}$ Discourse markers are "sequentially dependent elements which bracket units of talk (...). Sometimes these units are sentences, but sometimes they are propositions, speech acts or tone units (...). Markers occur at the boundaries of units as different as tone groups, sentences, actions, verses, and so on (...)" (Schiffrin, 1987). Our classification and analysis of discourse markers were based on Portolés (1998).
} 
stories). The six stories were expressively read off a teleprompter by the same two preschool teachers from the preliminary study, in two different conditions, one with accompanying beat gestures and the other without, for a total of 24 stories. When they read a story in the no-beat condition, the storytellers were asked to use child-directed speech but not produce beat gestures. In the beat condition, they were also asked to use child-directed speech, but to use an outward-directed beat gesture whenever they said a discourse marker and an inward-directed beat gesture when they said a focal content word, both of these elements being highlighted in boldface on the teleprompter text they were reading. Moreover, the two storytellers were asked to use a similing face in a consistent way across items and conditions.

Furthermore, the two storytellers were trained to produce the target items with exactly the same prosody in both the no-beat and the beat conditions. After they had practiced, each storyteller recorded two versions of each of the six stories in the two conditions (6 stories $\times 2$ conditions $\times 2$ versions) (see figure 3 ). The recordings were carried out in an experimental laboratory at the Universitat Pompeu Fabra. The storyteller performances were carefully monitored by the three authors of the study, in particular to make sure both storytellers maintained consistency in synchronizing their use of beat gestures with the corresponding target items. After the recording session, the first author compared the two versions of the narrative and selected the best performance.

The selected recordings were edited using the AVID video-editing programme (Avid Technology, Inc., 2016). In order to confirm that each storyteller had consistently used the same prosody across no-beat/beat conditions, the audio tracks were acoustically analyzed using Praat software (Boersma \& Weenink, 2016). In terms of their prosodic content, first the target words were prosodically coded using Cat_ToBI (Prieto et al., 2015), with the $\mathrm{H}$ and L F0 points in every pitch accent manually marked, as were the starting and end points of the target accented syllables and target words. Next, a set of the three automatic measures were obtained for the speech fragment constituting each full narrative, namely average pitch, average duration, and average intensity. A set of seven Generalized Linear Mixed Models (GLMMs) (West, Welch, \& Galecki, 2007) were then performed to statistically test for significant differences between the following prosodic measures across the two conditions: (a) pitch range, meaning the distance between the minimum and maximum pitch of $\mathrm{L}+\mathrm{H}^{*}$ pitch accents; (b) the duration of the target accented syllables; (c) the duration of the target words; (d) 
the mean pitch of the whole narrative; (e) the mean duration of the whole narrative; and (f) the mean intensity of the whole narrative. In all analyses, Condition was set as fixed factor, and a random intercept was set for both Speaker and Narrative. No statistically significant effects of Condition were found for any of the three prosodic variables, namely pitch range (results either in Hertz: $F(1,179)=.001, \beta=.374, S E=13.228, p=$ .977 ; or in semitones: $F(1,179)=.092, \beta=-.269, S E=.885, p=.761)$, accented syllable duration $(F(1,202)=.865, \beta=-.008, S E=.008, p=.353)$, or target word duration $(F(1,126)=.006, \beta=.001, S E=.016, p=.938)$. As for general phonetic measures covering each full discourse, no significant effect was found for mean pitch in $\mathrm{Hz}(F(1,20)=.001, \beta=.165, S E=4.735, p=.972)$, mean duration of the discourse $(\mathrm{F}(1,20)=.003, \beta=.075, S E=.437, p=.865)$, or mean intensity of the discourse $(F(1$, $20)=.028, \beta=.090, S E=.534, p=.868)$. Thus, no significant differences were found in prosody across no-beat/beat conditions.
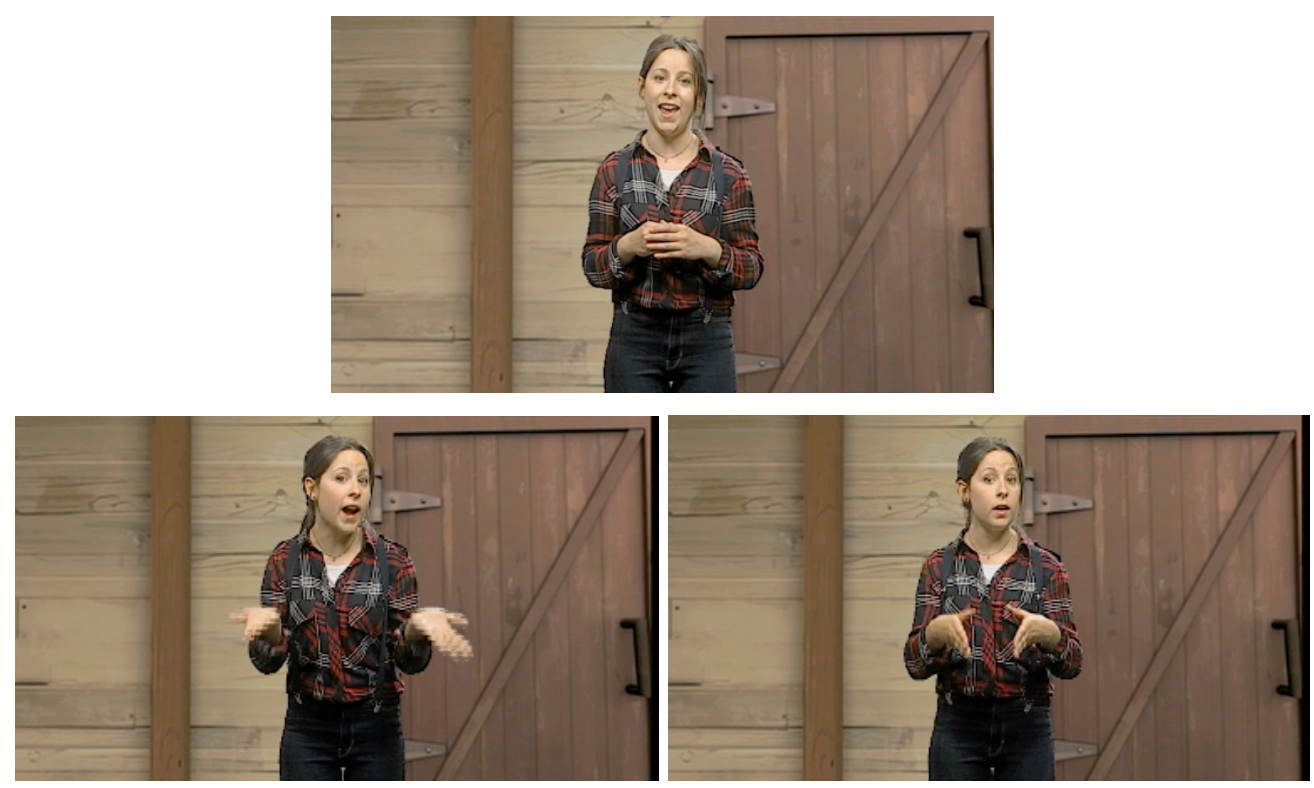

Figure 3. Stills from a stimulus training video showing one of the two storytellers telling one of the six stories in two conditions. Top panel: story being told in the no-beat condition. The storyteller refrains from making gestures as she tells the story. Bottom panels: story being told in the beat condition. Bottom left: the outward movement beat gesture. Bottom right: the inward movement beat gesture. The individual whose face appears here has given signed consent for her image to be published in this article.

\subsection{Experimental procedure}

Prior to the experiment, matched random assignment was used to assign the 44 participating children to one of the two conditions in such a way that the mean ages of the two treatment groups were equivalent. Thus, 21 children were assigned to the no- 
beat condition (mean age $=5.86, S D=0.56$ ) and 23 were assigned to the beat condition (mean age $=6.01, S D=0.58)$.

The study used a between-subject pretest-posttest design which is schematically illustrated in figure 4. First, in the pretest, the child was asked to watch two animated cartoons and then tell the story of what had happened to an experimenter. This part was followed by the training session, in which the child was shown six videotaped stories in one condition (i.e., no-beat or beat). Finally, in the posttest the child repeated the same task as in the pretest, but with two other cartoons. For each condition, a total of eight counterbalanced versions were created in which the order of the pretest and posttest cartoons, the six training stories and the two storytellers alternated.

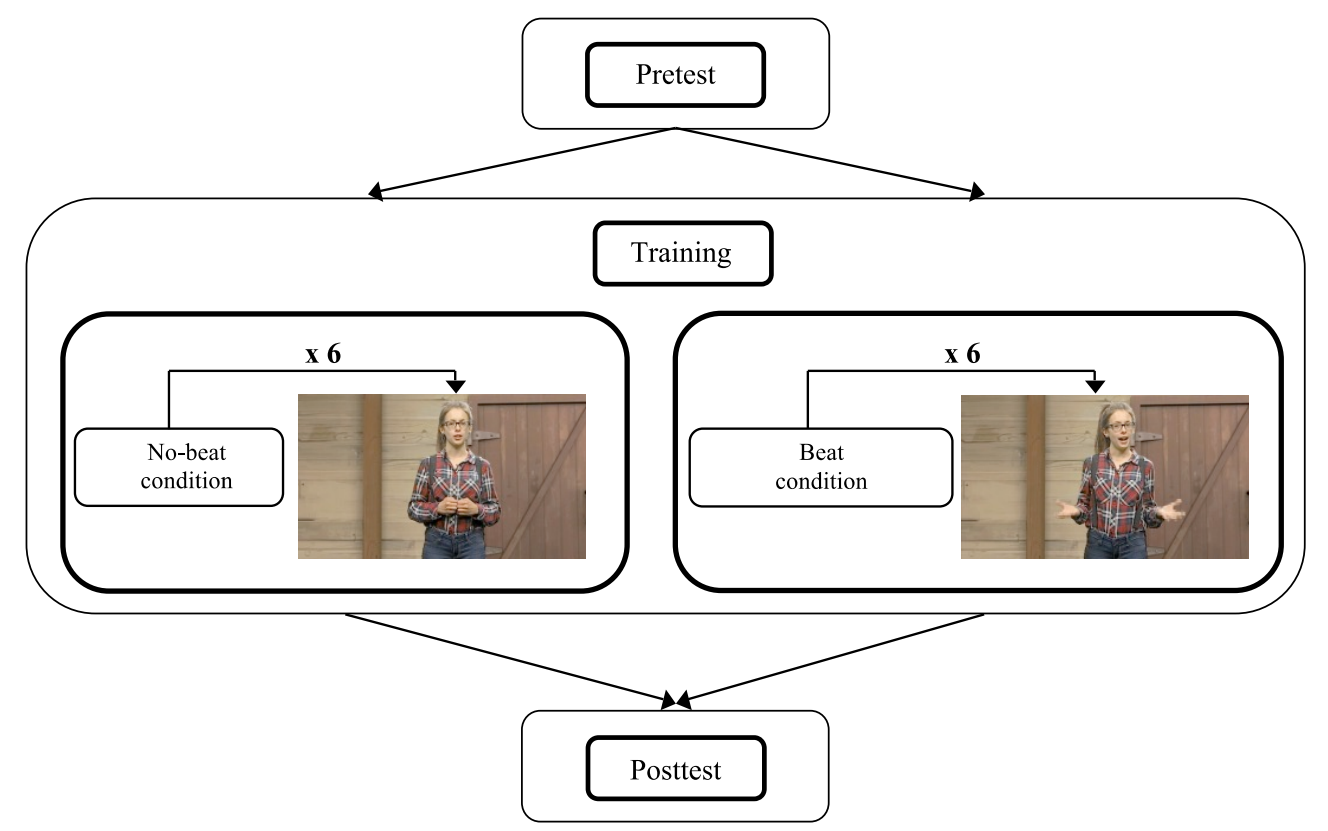

Figure 4. Overall experimental procedure. The individual whose face appears here has given signed consent for her image to be published in this article.

The participants were individually tested in a quiet classroom at their school and videotaped in all phases of the task (see figure 5 for a diagram of the experimental setup). The whole session lasted approximately 20-25 minutes. 


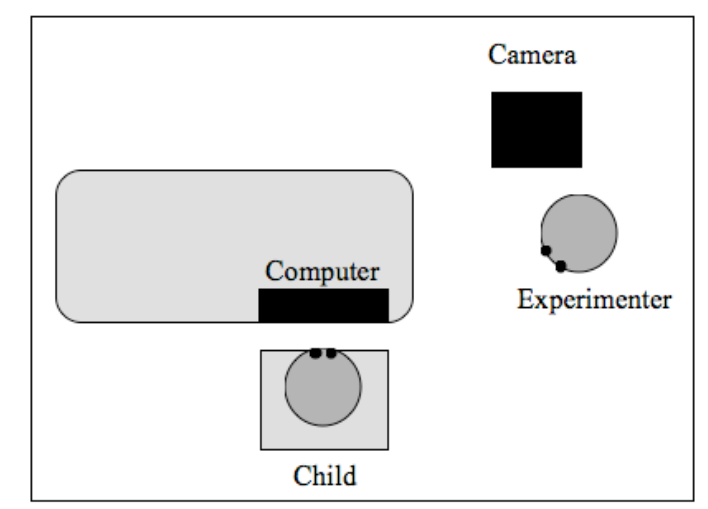

Figure 5. Experimental setup. The child was seated facing a laptop computer on which the pretest, training, and posttest videos were shown but stood in front of the experimenter to recount the story he or she had seen in the pretest and posttest cartoon videos. The experimenter sat in front of the child to interact with him/her but could not see the screen of the laptop. The video camera was located behind the shoulder of the experimenter to record the child's behavior when either sitting or standing.

\subsubsection{Pretest}

For the pretest, the child was seated facing a laptop computer and the experimenter, who explained what was going to happen. The child then put on headphones and watched two cartoons, the first one featuring only one character (see Appendix A for Cartoons A or C), the second featuring two (see Appendix A for Cartoons B or D).

After each clip, the child was asked to stand up and retell the story to the experimenter, who pretended not to have watched the video previously. If the child did not respond readily, he or she was prompted with a question like "Em pots explicar la història?" (“Can you tell me the story?"). The task was presented like a game, since the experimenter had several pictures in her hand from which she had to choose the picture that was most closely related to the story that the child was retelling. The retelling continued until the child indicated that he or she had finished or stopped for more than 10-15 seconds without clearly ending the narrative and had no further comment when the experimenter asked "I, què més?" (“Anything else?"). At this point, the experimenter gave positive feedback such as "M'agrada molt com expliques la història, així puc endevinar quin dibuix és!" ("I like the way you told the story very much, so I can easily guess which picture it is!") and showed the child the picture corresponding to the cartoon. 


\subsubsection{Training session}

After the pretest, the child again put on the headphones and watched six videos showing the two storytellers telling a total of six stories. The same set of six stories were shown to each child, in the same condition for each child, but the children were shown them in different orders of story and storyteller.

\subsubsection{Posttest}

The posttest followed exactly the same procedure as the pretest. The same four cartoons were used for all the children, one pair in the pretest and another pair in the posttest. The pairing remained constant, but the order of the two pairs was varied.

\subsection{Coding system}

The resulting 176 video-recordings ( 44 children $\times 4$ retellings) of the children's pretest and posttest performances were analyzed according to a speech-coding scheme designed to measure a variety of features related to the quality of the children's narrative structure.

\subsubsection{Narrative structure scores}

To obtain a measure of overall narrative structure, we used a modified version of the coding system applied by Demir et al. (2014) and Demir et al. (2015a), ${ }^{10}$ which in turn is based on Stein and Glenn's (1979) approach to narrative structure in children. According to this approach, the organizational quality of a child's narrative can be measured in terms of four main features, namely the presence of an animate protagonist, temporal structure, causal structure, and goal-directed action. Each feature is considered to be a prerequisite for the next, and thus narratives with more of these features are rated more complex than stories with fewer of them. The rubric we used to score the narratives produced by child participants is shown in figure 6. A child's narrative was rated as a "complete goal-based narrative" and received the highest score if it showed signs of causal and temporal structuring and specified the initiating event or challenge facing the protagonist, his/her consequent goal, how he/she attempted to achieve the goal, and the eventual outcome of that attempt. It should be noted that in retelling the

\footnotetext{
${ }^{10}$ For more details on this narrative coding system, see Demir et al. (2014:819, "Measures" section) and Demir et al. (2015a:6-7, "Narrative structure in speech" section).
} 
cartoons children occasionally remembered that some object or animal had been involved but could not quite remember which one. In such cases, we counted this as a successful retelling only if the object they named was similar in kind to the object in the cartoon-for example, if the child referred to the mouse as a "squirrel". An example of a scored narrative can be seen in Appendix C.

\begin{tabular}{|c|l|}
\hline Score & Features of the narrative \\
\hline 0 & $\begin{array}{l}\text { A narrative with no structure. It does not even contain a descriptive sequence; the } \\
\text { story is not remembered. }\end{array}$ \\
\hline 1 & $\begin{array}{l}\text { A descriptive sequence. This is a narrative that includes the physical and personality } \\
\text { characteristics of an animate protagonist with no mention of a sequence of actions (i.e., } \\
\text { no temporal structure). }\end{array}$ \\
\hline 2 & $\begin{array}{l}\text { An action sequence. This is a narrative with actions described in a temporal order } \\
\text { (actions follow one another in time) but in which the actions are not causally organized } \\
\text { (i.e., if there was one event causing the following event or events, the story was } \\
\text { categorized as an action sequence) }\end{array}$ \\
\hline 3 & $\begin{array}{l}\text { A reactive sequence. This contains actions that are temporally and causally organized } \\
\text { but does not include either the protagonist's goal }{ }^{11} \text { or the attempt to achieve the goal or } \\
\text { neither of the two. The outcome is always mentioned here. }\end{array}$ \\
\hline 4 & $\begin{array}{l}\text { An incomplete goal-based narrative. This includes temporal and causal structure, a } \\
\text { goal statement and/or description of an attempt to achieve the goal, but no information } \\
\text { about the outcome. }\end{array}$ \\
\hline 5 & $\begin{array}{l}\text { A goal-based narrative. This includes not only temporal and causal structure as well } \\
\text { as a goal statement, description of an attempt to achieve the goal, and the final } \\
\text { outcome. }\end{array}$ \\
\hline 6 & $\begin{array}{l}\text { A complete goal-based narrative. This contains not only temporal and causal } \\
\text { structure but also all the main features noted above. Moreover, the story is fleshed out } \\
\text { with details including the initiating event. }\end{array}$ \\
\hline
\end{tabular}

Figure 6. Rubric for scoring of child-produced retelling narratives (based on Demir et al., 2014, and Demir et al., 2015a)

\subsection{Reliability of the coding}

To test the reliability of the narrative structure coding, two independent coders conducted an inter-transcriber reliability test with a random subset of $20 \%$ of the data (40 cases). Overall agreement between the two coders and the author of the study was $66 \%$. The fixed-marginal multirater kappa statistic value was 0.43 , suggesting a moderate degree of agreement between coders given the high number of categories (from 0 to 6).

\footnotetext{
${ }^{11}$ The goal of the protagonist was regarded as correctly described if the child interpreted it with a mental state verb (e.g., to want). The goal could be explicit (e.g., "he wants to hang up the laundry") or implicit (e.g., "he was fed up with the clothes always falling on the ground"). Moreover, explicit mention of the discovery of a solution (e.g., "he/they found a solution", "he/they had an idea", etc.) was also counted as the description of a goal.
} 


\section{RESULTS}

One GLMM was run using SPSS Statistics 23.0 (SPSS Inc., Chicago IL) with narrative structure scores as the dependent variable.

\subsection{Narrative structure scores}

In order to assess the potential effects of the beat training condition on children's narrative structure abilities, we ran a GLMM with the overall narrative structure ratings as a dependent variable, training Condition (two levels: no-beat and beat) and Test (two levels: pretest and posttest), and the interaction Condition $\times$ Test as fixed factors, and Subject and Item (i.e., the four stories used in the pretest and posttest) as random factors. Bonferroni pairwise comparison post hoc tests were carried out for the significant main effects and interactions.

The results of the GLMM analysis showed a main effect of Condition $(F(1,172)$ $=8.041, p=.005)$, with higher narrative structure scores in the beat condition $(\beta=$ $.441, S E=.156, p=.005)$ than in the no-beat condition. Regarding the effect sizes, the $\beta$ regression coefficient indicates that the probability of a child in the beat condition having a greater narrative structure score is about .441 times higher (in a scale from 0 to 6) than for a child in the no-beat condition. A main effect of Test $(F(1,172)=19.691, p$ $=.000)$ was also found, with posttest narrative structure scores better $(\beta=.597, S E=$ $.135, p=.000)$ than pretest scores. In this case, the probability of a child's posttest narrative to have higher assessment scores is about .597 times higher (in a scale from 0 to 6) than for a child's pretest score.

A significant interaction between Condition and Test was found $(F(1,172)=$ 4.705, $p=.031$ ), indicating that narrative performances differed depending on the condition and the test. Post hoc analyses revealed that while beat and no-beat conditions did not significantly differ in the pretest part $(\beta=.149, S E=.205, p=.467)$, they did so in the posttest, with greater narrative structure scores in the beat condition $(\beta=.733$, $S E=.207, p=.000)$ than in the no-beat condition. The $\beta$ scores indicate that the probability of a child's posttest narrative to have higher assessment scores is about .733 times higher (in a scale from 0 to 6 ) in the beat condition than in the no-beat condition. By contrast, considering differences in terms of condition, post hoc analyses revealed significant differences between pretest and posttest scores in the beat condition, with better narrative structure scores in the posttest $(\beta=.889, S E=.186, p=.000)$ than in 
the pretest. The probability of a child in the beat condition having a greater quality posttest narratives is about .889 higher (in a scale from 0 to 6 ) than for the pretest narratives. Crucially, no significant differences between pretest and posttest were found in the no-beat condition $(\beta=.305, S E=.195, p=.119)$. Therefore, the results show that participants who undertook the beat training condition obtained higher narrative structure scores in the posttest than in the pretest part while participants who had training without beat gestures did not.

Figure 7 shows the mean overall narrative structure scores (from 0 to 6 ), broken down by training condition (no-beat vs. beat) and test (pretest vs. posttest). The graph shows that the posttest narrative structure scores in the beat condition outperformed those in the no-beat condition.

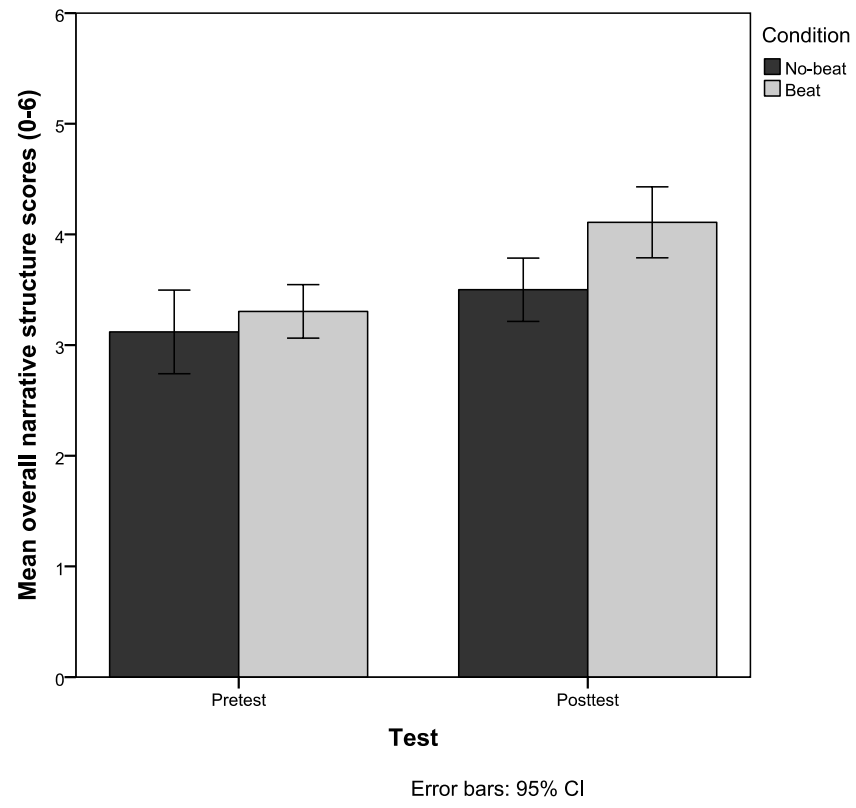

Figure 7. Mean overall narrative structure scores from 0 to 6, broken down by training condition (nobeat vs. beat) and test (pretest vs. posttest). Error bars represent 95\% confidence intervals of the means.

\section{DISCUSSION AND CONCLUSIONS}

Previous research has demonstrated that gestures and prosody promote benefits for children's early language development and predict later language abilities. Though previous studies have found that co-speech gestures (mostly representational gestures) play an important role in children's narrative discourse development, as far as we know, this is the first time that a study has tested the effects of observing narratives with beat gestures on the improvement of children's narrative performance. Our goal was to 
examine whether a short training session with beat gestures could favor children's narrative performances as measured by narrative structure scores in a narrative discourse production task. Through a between-subject training study with a pretest and immediate posttest design, we found that children who were assigned to the beat training condition manifested positive changes in the quality of their posttest narratives, clearly seen in higher narrative structure scores. In our view, it is the supplementary highlighting role that beat gestures play in marking focus and discourse structure in language which most likely boosted the children's subsequent performance, resulting in more detailed, better organized, and more complete goal-based narratives that reflected an understanding of temporal and causal structure.

The results of the present study extend our knowledge about the positive benefits of beat gestures in cognitive processes and language development, which have previously been specifically reported in connection with information recall (e.g., So et al, 2012; Austin \& Sweller, 2014; Igualada et al. 2017; Llanes-Coromina et al., 2018) and narrative discourse comprehension (Llanes-Coromina et al., 2018). In this regard, beat gestures seem to differ from other kinds of potential visual highlighters because they are related to the language-related areas of the brain and not the visual-perception areas (Holle et al., 2012; Biau \& Soto-Faraco, 2013; Wang \& Chu, 2013).

This study extends the results of previous research showing the benefits of observing beat gestures in promoting narrative performances (Shattuck-Hufnagel et al., 2016; Demir et al., 2014; Demir et al., 2015a). Importantly, to our knowledge, our study is the first study to demonstrate that a short training session featuring narratives produced with beat gestures can have an immediate positive effect on children's narrative performances, specifically on narrative structure. Including beat gestures in a story thus leads to better narrative retelling scores. As we initially hypothesized, the special role of beat gestures as highlighters of linguistic functions such as focus marking, rhythmic marking, and discourse structure marking (Shattuck-Hufnagel et al., 2016; Dimitrova et al., 2016) suggests that they can play a role in developing narrative performance in children.

As noted above, the basic tenets of the Gesture-for-Conceptualization Hypothesis by Kita et al. (2017) can offer conceptual support for the present findings on the beneficial role of observing gestures in cognitive and linguistic production. As we have seen, according to that hypothesis a representational gesture "activates, manipulates, packages and explores spatio-motoric representations for the purposes of 
speaking and thinking" (p. 36). By assuming that the properties of representational gestures also apply to beat gestures, we suggest that these gestures similarly help activate, manipulate, and package discourse and pragmatic information which can help children to produce better narratives (see their discussion about the extension of these findings to abstract domains via metaphoric gestures). Importantly, the model claims that the influence of gesture encompasses both production as well as observation effects. As they contend, "gesture's influence is not limited to speakers; speakers' schematization of information in gesture influences listeners' thinking, as well. In these ways, gesture plays a central role in human cognition" (p. 47).

Some limitations of this work must be acknowledged. The main limitation of this study concerns the use of a brief training paradigm that analyses short-term effects. Though the study demonstrates the positive short-term effects of the storyteller's use of beat gestures on children's narrative structure scores, it can make no claims about possible long-term effects. Thus future work should explore on the one hand whether this sort of narrative training including beat gestures can have any long-term effect, and on the other the possible impact of longer training periods. Furthermore, one might argue that the naturalness of the training materials used here could be improved upon in terms of their ecological validity. Although having the adult storytellers read narratives off a teleprompter helped us to control the acoustic features of their speech and the visual features of their gestures, this methodology may not accurately reflect what occurs in a natural and spontaneous context of child-directed storytelling. Finally, it would be interesting to code children's gestures during their narrative productions to assess the influence of gesture use in the improvement of narrative abilities after training.

In sum, this study provides important information about the positive effects of beat gestures on children's narrative performance, lending support to studies that point to a co-development and mutual interaction between co-speech gestures and language (e.g., Colletta et al., 2015; Sekine \& Kita, 2015). Specifically, it is of interest to note that even a relatively short training session with beat gestures had a noticeable effect on children's retelling abilities. This may have important implications for our understanding of how children develop narrative skills and for educational practices in the teaching of narrative abilities at the preschool level. Indeed, it is believed that using a variety of storytelling activities, which include the use of beat gestures (as well as other types of naturalistic gestures), may facilitate children's language development. 


\section{REFERENCES}

Alibali, M. W., Evans, J. L., Hostetter, A. B., Ryan, K., \& Mainela-Arnold, E. (2009). Gesture-speech integration in narrative: Are children less redundant than adults? Gesture, 9(3), 290-311. doi:10.1075/gest.9.3.02ali

Austin, E., \& Sweller, N. (2014). Presentation and production: The role of gesture in spatial communication. Journal of Experimental Child Psychology, 122(1), 92103. doi: $10.1016 /$ j.jecp.2013.12.008

Avid Technology, Inc. (2016). Pro Tools 11 [computer software]. Available from https://www.avid.com/pro-tools

BAvin, E. (2014). Gestures in Communicative Development (Overview). In P. Brooks \& V. Kampe (Eds.), Encyclopedia of Language Development (pp. 248-252). Thousand Oaks, CA: SAGE.

Biau, E., \& Soto-FARAco, S. (2013). Beat gestures modulate auditory integration in speech perception. Brain \& Language, 124(2), 143-152. doi : 10.1016/j.bandl.2012.10.008

Blake, J., Myszczyszyn, D., Jokel, A., \& Bebiroglu, N. (2008). Gestures accompanying speech in specifically language-impaired children and their timing with speech. First Language, 28(2), 237-253. doi: 10.1177/0142723707087583

Boersma, P., \& WeEninK, D. (2016). Praat: doing phonetics by computer (Version 6.0.23) [computer software]. Available from http://www.praat.org/

Bosch, L., \& Sebastián-Galles, N. (2001). Evidence of Early Language Discrimination Abilities in Infants from Bilingual Environments. Infancy, 2(1), 29-49. doi: 10.1207/S15327078IN0201_3

Colletta, J. M., Guidetti, M., Caprici, O., Cristilli, C., Demir, O. E., KuneneNiCOLAS, R. N., \& LEVINE, S. (2015). Effects of age and language on co-speech gesture production: an investigation of French, American, and Italian children's narratives. Journal of Child Language, 42(1), 122-145. doi: 10.1017/S0305000913000585

Colletta, J. M., PellenQ, C., \& Guidetti, M. (2010). Age-related changes in cospeech gesture and narrative: evidence from French children and adults. Speech Communication, 52(6), 565-576. doi: 10.1016/j.specom.2010.02.009 
Demir, Ö. E., Fisher, J. A., Goldin-Meadow, S., \& Levine, S. C. (2014). Narrative processing in typically developing children and children with early unilateral brain injury: Seeing gesture matters. Developmental Psychology, 50(3), 815828. doi: $10.1037 / \mathrm{a} 0034322$

Demir, Ö., \& KÜnTAY, A. (2014). Narrative Development. In P. Brooks \& V. Kampe (Eds.), Encyclopedia of Language Development (pp. 393-397). Thousand Oaks, CA: SAGE.

Demir, Ö. E., LEVINE, S. C., \& Goldin-MEAdow, S. (2010). Narrative skill in children with early unilateral brain injury: a possible limit to functional plasticity. Developmental Science, 13(4), 636-647. doi:10.1111/j.14677687.2009.00920.x

Demir, Ö. E., Levine, S. C., \& Goldin-Meadow, S. (2015a). A tale of two hands: children's early gesture use in narrative production predicts later narrative structure in speech. Journal of Child Language, 42(3), 662-681. doi: 10.1017/S0305000914000415

Demir, Ö. E., Rowe, M. L., Heller, G., Goldin-Meadow, S. \& Levine, S. C. (2015b). Vocabulary, syntax, and narrative development in typically developing children and children with early unilateral brain injury: early parental talk about the "there-and-then" matters. Developmental Psychology, 51(2), 161-175. doi: 10.1037/a0038476

Dimitrova, D., Chu, M., WAng, L., ÖzyÜreK, A., \& HAgoort, P. (2016). Beat that word: how listeners integrate beat gesture and focus in multimodal speech discourse. Journal of Cognitive Neuroscience, 28(9), 1255-1269. doi:10.1162/jocn_a_00963

DuinmeiJer, I., DE JONG, J., \& SchePer, A. (2012). Narrative abilities, memory and attention in children with a specific language impairment. International Journal of Language \& Communication Disorders, 47(5), 542-555. doi: 10.1111/j.1460-6984.2012.00164.x

Faul, F., Erdfelder, E., Buchner, A., \& LANG, A.-G. (2009). Statistical power analyses using $\mathrm{G}^{*}$ Power 3.1:Tests for correlation and refression analyses. Behavior Research Methods, 41, 1149-1160. doi: 10.3758/BRM.41.4.1149

Goldin-Meadow, S., \& Butcher, C. (2003). Pointing: Where language, culture, and cognition meet. In S. Kita (Ed.), Pointing toward two word speech in young children (pp. 85-107). Hillsdale, NJ: Lawrence Erlbaum Associates. 
Griffin, T. M., HemPhill, L., CAMP, L., \& Wolf, D. P. (2004). Oral discourse in the preschool years and later literacy skills. First Language, 24(2), 123-147. doi: $10.1177 / 0142723704042369$

Holle, H., Obermeier, C., Schmidt-Kassow, M., Friederici, A.D., Ward, J., \& GunTER, T. C. (2012). Gesture facilitates the syntactic analysis of speech. Frontiers in Psychology, 3(74), 1-12. doi: 10.3389/fpsyg.2012.00074

Hostetter, A. B., \& Alibali, M. W. (2008). Visible embodiment: Gestures as simulated action. Psychonomic Bulletin \& Review, 15(3), 495-514. doi: 10.3758/PBR.15.3.495

Igualada, A., Esteve-Gibert, N., \& Prieto, P. (2017). Beat gestures improve word recall in 3- to 5-year-old children. Journal of Experimental Child Psychology, 156, 99-112. doi: 10.1016/j.jecp.2016.11.017

IVERSON, J. M., \& Goldin-MEAdow, S. (2005). Gesture paves the way for language development. Psychological Science, 16(5), 367-371. doi: 10.1111/j.09567976.2005.01542.x

Kelly, S. D., McDevitT, T., \& Esch, M. (2009). Brief training with co-speech gesture lends a hand to word learning in a foreign language. Language and Cognitive Processes, 24(2), 313-334. doi: 10.1080/01690960802365567

Kelly, S. D., ÖZyÜreK, A., \& MAris, E. (2010). Two Sides of the Same Coin: Speech and Gesture Mutually Interact to Enhance Comprehension. Psychological Science, 21(2), 260-267. doi: 10.1177/0956797609357327

Kendon, A. (1980). Gesticulation and speech: two aspects of the process of utterance. In M. R. Key (Ed.), The Relationship of Verbal and Nonverbal Communication (pp. 207-227). The Hague: Mouton.

KENDON, A. (1995). Gestures as illocutionary and discourse structure markers in Southern Italian conversation. Journal of Pragmatics, 23(3), 247-279. doi: 10.1016/0378-2166(94)00037-F

Kita, S., Alibali, M. W., \& CHU, M. (2017). How do gestures influence thinking and speaking? The gesture-for-conceptualization hypothesis. Psychological Review, 124(3), 245-266. doi: 10.1037/rev0000059

Kushch, O., Igualada, A., \& Prieto, P. (2018, in press). Prominence in speech and gesture favor second language novel word learning. Language, Cognition and Neuroscience. 
Kushch, O., \& Prieto, P. (2016). The effects of pitch accentuation and beat gestures on information recall in contrastive discourse. Proceedings from the 8th International Conference on Speech Prosody (pp. 922-925). Boston, USA.

Levinson, S. C., \& Holler, J. (2014). The origin of human multi-modal communication. Philosophical Transactions of the Royal Society of London. B, 369: 20130302. doi: 10.1098/rstb.2013.0302

Llanes-Coromina, J., Vilà-Giménez, I., Kushch, O., Borràs-Comes, J., \& Prieto, P. (2018). Beat gestures help preschoolers recall and comprehend discourse information. Journal of Experimental Child Psychology, 172(8), 168-188. doi: 10.1016/j.jecp.2018.02.004

LoEHR, D. P. (2012). Temporal, structural, and pragmatic synchrony between intonation and gesture. Laboratory Phonology, 3, 71-89. doi: 10.1515/lp-20120006

Macoun, A., \& Sweller, N. (2016). Listening and watching: The effects of observing gesture on preschoolers' narrative comprehension. Cognitive Development, 40, 68-81. doi: 10.1016/j.cogdev.2016.08.005

Mathew, M., Yuen, I., \& Demuth, K. (2017). Talking to the beat: Six-year-olds' use of stroke-defined non-referential gestures. First Language, 38(2) 1-18. doi: $10.1177 / 0142723717734949$

MAYBERRY, R. I., \& NiCOLADIS, E. (2000). Gesture Reflects Language Development: Evidence from Bilingual Children. Current Directions in Psychologycal Science, 9(6), 192-196. doi: 10.1111/1467-8721.00092

MCNeILl. (1992). Hand and Mind: What Gestures Reveal about Thought. Chicago, University of Chicago Press.

MumFord, K. H., \& KiTA, S. (2014). Children use gesture to interpret novel verb meanings. Child Development, 85(3), 1181-1189. doi: 10.1111/cdev.12188

Nicoladis, E., Mayberry, R. I., \& Genesee, F. (1999). Gesture and early bilingual development. Developmental Psychology, 35(2), 514-526.

ÖZÇALIŞKAN, Ş., \& GOLDIN-MEADOW, S. (2005). Gesture is at the cutting edge of early language development. Cognition, 96(3), B101-B113. doi: 10.1016/j.cognition.2005.01.001

PortolÉs, J. (1998). Marcadores del discurso. Barcelona: Ariel.

Prieto, P., Borràs-Comes, J., Cabré, T., Crespo-Sendra, V., Mascaró, I., Roseano, P., Sichel-Bazin, R. \& VAnrell, M. M. (2015). Intonational 
phonology of Catalan and its dialectal varieties. In S. Frota. \& P. Prieto (Eds.), Intonational variation in Romance (pp. 9-62). Oxford: Oxford University Press.

Prieto, P., Cravotta, A., Kushch, O., Rohrer, P., \& Vilè-Giménez, I. (2018). Deconstructing beat gestures: a labelling proposal. Proceedings from the 9th International Conference on Speech Prosody. Poznań, Poland.

SCHIFFrin, D. (1987). Discourse Markers (Studies in Interactional Sociolinguistics 5). Cambridge: Cambridge University Press.

SEKINE, K., \& KitA, S. (2015). The parallel development of the form and meaning of two-handed gestures and linguistic information packaging within a clause in narrative. Open Linguistics, 1(1), 490-502. doi: 10.1515/opli-2015-0015

Shattuck-Hufnagel, S., Ren, A., Mathew, M., Yuen, I., \& Demuth, K. (2016). Non-referential gestures in adult and child speech: Are they prosodic? Proceedings from the 8th International Conference on Speech Prosody (pp. 836-839). Boston, USA.

So, W. C., Chen-Hui, C. S., \& Wei-Shan, J. L. (2012). Mnemonic effect of iconic gesture and beat gesture in adults and children: Is meaning in gesture important for memory recall? Language and Cognitive Processes, 27(5), 665-681. doi: $10.1080 / 01690965.2011 .573220$

Stein, N. L., \& GlenN, C. G. (1979). An analysis of story comprehension in elementary children (Vol. 2.). Norwood, NJ: Ablex.

TELLIER, M. (2008). The effect of gestures on second language memorisation by young children. Gesture, 8(2), 219-235. doi: 10.1075/gest.8.2.06tel

Theakston, A., Coates, A., \& Holler, J. (2014). Handling agents and patients: Representational cospeech gestures help children comprehend complex syntactic constructions. Developmental Psychology, 50(7), 1973-1984. doi: $10.1037 / \mathrm{a} 0036694$

ThOmpson, L. A. (1995). Encoding and memory for visible speech and gestures: A comparison between young and older adults. Psychology and Aging, 10(2), 215-228. doi: 10.1037/0882-7974.10.2.215

Wagner, P., Malisz, Z., \& Kopp, S. (2014). Gesture and speech in interaction: An overview. Speech Communication, 57, 209-232. doi: 10.1016/j.specom.2013.09.008 
WANG, L., \& ChU, M. (2013). The role of beat gesture in pitch accent in semantic processing: An ERP study. Neuropsychologia, 51(13), 2847-2855. doi: 10.1016/j.neuropsychologia.2013.09.027

West, B., Welch, K. B., \& Galecki, A. T. (2007). Linear mixed models: A practical guide using statistical software. New York: Chapman \& Hall/CRC. 


\section{Appendix A: Narrative structure of all the stories in the animated cartoons}

\begin{tabular}{|l|l|}
\hline Initiating event: After the mouse has inflated the inflatable \\
apple tree, he sniffs an apple. \\
Goal: The mouse wants to take an apple from the tree. \\
Attempt: The mouse picks an apple from the tree. \\
Outcome: The tree deflates automatically so the mouse can not \\
eat the apple.
\end{tabular}




\section{Appendix B: English translations of the six training stories}

\begin{tabular}{|c|c|}
\hline 1st story & $\begin{array}{l}\text { Once upon a time, a duck was walking to school. Suddenly, it started to } \\
\text { rain, and the duck didn't have an umbrella. In the end, he came up with a } \\
\text { solution: he put his hood on his head to protect himself from the rain. }\end{array}$ \\
\hline 2nd story & $\begin{array}{l}\text { Once upon a time, a rabbit went for walk in the mountains. Suddenly, some } \\
\text { cows started to walk towards him and he was scared. In the end, he found a } \\
\text { solution: he stood still behind a tree until the cows left. }\end{array}$ \\
\hline 3rd story & $\begin{array}{l}\text { Once upon a time, there was a horse that was hungry. Suddenly, he realized } \\
\text { that there were no biscuits in the cupboard, because he had eaten them all. In } \\
\text { the end, he thought of a solution: he made biscuits in the oven. }\end{array}$ \\
\hline 4th story & $\begin{array}{l}\text { Once upon a time, there was a hen that was sleepy. Suddenly, she fell } \\
\text { asleep on the sofa, but her alarm clock woke her up. She had forgotten that } \\
\text { the following day was her birthday and that she was planning to buy candles } \\
\text { to celebrate it. In the end, she found a solution: she bought some enormous } \\
\text { candles and was therefore able to celebrate her birthday. }\end{array}$ \\
\hline 5th story & $\begin{array}{l}\text { Once upon a time, a pig was playing football in the park. Suddenly, he } \\
\text { realized that it was late and he had to go back home, because otherwise his } \\
\text { mother would get angry. In the end, he thought of a solution: he took a } \\
\text { shortcut to get home. That way, he managed to not arrive late and his } \\
\text { mother did not get angry. }\end{array}$ \\
\hline 6th story & $\begin{array}{l}\text { Once upon a time, a cat was staying at his grandparents' house in summer. } \\
\text { Suddenly, he remembered that he had to do his homework, because } \\
\text { otherwise his grandparents wouldn't wait for him to go to the beach. In the } \\
\text { end, he came up with a solution: he did the homework before his } \\
\text { grandparents arrived, and that way he was able to go to the beach. }\end{array}$ \\
\hline
\end{tabular}




\section{Appendix C: Example of a child-produced narrative}

Below is a transcript of a child retelling one of the cartoon stories from the posttest task. The English translation which follows is marked-up to illustrate scoring in terms of narrative structure.

Child: Hi havia una vegada, un esquirol que volia penjar la roba, però feia tant de vent que no podia penjar els seus mitjons, i a sobre estaven tots trencats. I va trobar una solució. Va desfer un fil i va començar a posar els mitjons, i després ho va tornar a enganxar al fil, i ja va poder que s'assequessin els mitjons.

English translation: [Once upon a time, a squirrel wanted to hang up the clothes $\boldsymbol{G O A L}$ ], [but it was windy and he couldn't hang up his socks, and they were all worn out. INITIATING EVENT] [And he found a solution. He untied the clothesline, passed the socks through it, and then retied it. ATTEMPT TO ACHIEVE THE GOAL] [And he got the socks to dry. OUTCOME]

Here the child tells a complete, temporally and causally structured story, as all the linguistic elements are well linked. Regarding the narrative structure items that constituted scoring points, the child mentioned the initiating event, the goal of the protagonist, the attempt to achieve this goal, and the outcome of this attempt (these items have been separated by square brackets). Moreover, the retelling includes significant detail. Thus this particular retelling received the maximum score of 6 . 